\title{
Cartografía de la peligrosidad por deslizamientos en el municipio de Mayarí, Holguín
}

\section{Hazard mapping due to landslides in Mayarí municipality, Holguin}

\author{
Yexenia Viltres-Milán ${ }^{1 *}$, Rafael Guardado-Lacaba ${ }^{2}$, Lázaro D. Alfonso-Olivera ${ }^{1}$ \\ ${ }^{1}$ Centro Nacional de Investigaciones Sismológicas, Bayamo, Granma, Cuba. \\ ${ }^{2}$ Universidad de Moa, Holguín, Cuba. \\ *Autor para la correspondencia: yviltres87@gmail.com
}

\section{Resumen}

El propósito fue cartografiar los factores condicionantes y desencadenantes que generan peligro por deslizamientos en el municipio de Mayarí, provincia de Holguín. Para ello se empleó la Guía metodológica para el estudio de peligro, vulnerabilidad y riesgo por deslizamientos de terreno elaborada por el Grupo Nacional de Gestión de Riesgos, del año 2012. Las zonas con deslizamientos se identificaron mediante la observación e interpretación del modelo digital del terreno y revisando los mapas topográficos de 1985 del Instituto Cubano de Geodesia y Cartografía e imágenes aéreas obtenidas de Google Earth; sirvieron, además, de apoyo trabajos de campo, considerando eventos del pasado y la aplicación de los Sistemas de Información Geográfica. Como resultado se obtiene el mapa de peligrosidad por deslizamientos del municipio, a escala 1: 25 000, herramienta de utilidad para encarar los deslizamientos y planificar el desarrollo económico y social de Mayarí.

Palabras clave: Sistemas de Información Geográfica; cartografía; peligrosidad; deslizamientos; municipio de Mayarí.

\section{Abstract}

The purpose of this article was to map the conditioning and triggering factors that generate hazard due to landslides in the municipality of Mayarí, Holguín province. The Methodological Guide for the Study of Hazard, 
Vulnerability and Risk of Landslides, prepared by the National Risk Management Group in 2012, was used. By observing and interpreting the Digital Model of the soil and reviewing the topographic maps of 1985 of the Cuban Geodesy and Cartography Institute and aerial images obtained from Google Earth, sliding areas were identified. Field work was also useful, taking into account the application of Geographic Information Systems and past events. As a result, the landslide hazard map of the municipality of Mayarí was obtained, at a scale of 1: 25,000, a useful tool for dealing with the landslides and planning the economic and social development of the municipality

Keywords: Geographic Information Systems; mapping; dangerousness; landslides; Mayarí municipality.

\section{INTRODUCCIÓN}

En la provincia de Holguín las zonas montañosas son las más propensas a la ocurrencia de deslizamientos. El municipio de Mayarí, con el 57,6 \% de su área con relieve montañoso, uno de los más afectados por este tipo de fenómeno geológico con alto factor de riesgo, tanto para la población como para la economía. Esto tiene explicación en sus condiciones geológicas e ingeniero-geológicas debido a que, generalmente, se conjugan elementos que conducen a su ocurrencia, como son: la topografía, la sismicidad, la meteorización, las lluvias intensas y la acción antrópica.

Mayarí se localiza en el centro-este de la provincia de Holguín. Al norte limita con la bahía de Nipe, el océano Atlántico y los municipios de Banes y Antilla; al sur, con la provincia de Santiago de Cuba; al este, con el municipio de Frank País y al oeste con los municipios de Cueto y Báguanos (Figura 1). Su extensión territorial es de 1310,6 km². 


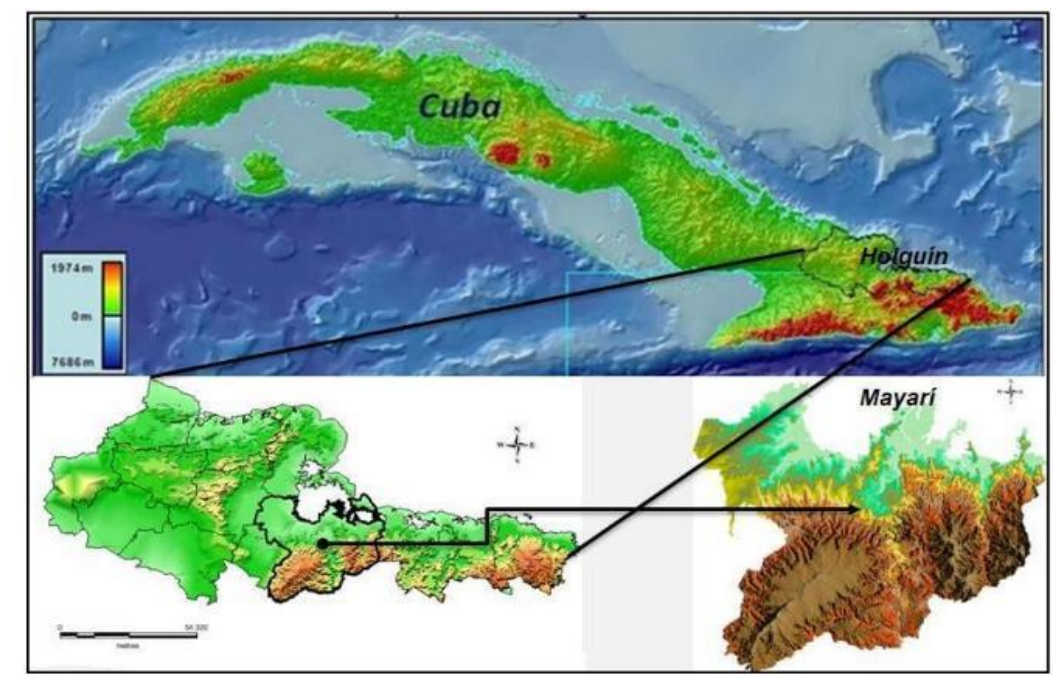

Figura 1. Mapa de ubicación del municipio de Mayarí.

La geomorfología del área bajo estudio exhibe dos macizos montañosos, Sierra de Nipe y Sierra Cristal. Su relieve ha sido condicionado tectónicamente y refleja las particularidades de la compleja estructura geológica que se obtiene como resultado de los movimientos compresivos de la orogenia cubana y las adquiridas en la etapa neotectónica.

En la Sierra Cristal se encuentra La Mensura, la mayor elevación del territorio, con 995 msnm. Coexisten diferentes categorías geomorfológicas determinadas por las diversas amplitudes de los movimientos neotectónicos, como son las montañas, las alturas y las llanuras. Las montañas fueron el resultado de ascensos neotectónicos moderados e intensos (Centro de Investigaciones y Servicios Ambientales -CISAT 2007).

Desde el punto de vista climático, el municipio presenta un régimen que se diferencia con la media nacional y provincial, dado por la posición que ocupa con respecto al anticiclón del Atlántico y a sus condiciones de relieve montañoso. La precipitación media en el área que comprende la meseta Pinares de Mayarí es de 1650 mm, a unos 600 msnm, según el Centro de Investigaciones y Servicios Ambientales (2007).

El municipio de Mayarí se enclava en el complejo ofiolítico Mayarí-Baracoa, específicamente en el macizo Mayarí-Cristal, localizado en el extremo oriental de la isla de Cuba. En este macizo se distinguen diferentes mantos de cabalgamiento, en los que se aprecian espejos de fricción y escamas tectónicas de diferentes espesores (Proenza 1998). Desde el punto de vista de la tectónica constituye un bloque hundido de tipo graben (intramontañoso) (Arango 1988). 
Rocas carbonatadas y terrígenas carbonatadas se distinguen en el área, bien diferenciadas, sobreyaciendo a las ultramafitas serpentinizadas del complejo intrusivo del Cretácico Superior. Presentan diferentes grados de alteración y han dado origen a varios tipos de harzburgitas $y$, en menor grado, dunitas y piroxenitas; ello se debió al intenso tectonismo sufrido por la región durante el Cretácico y el Paleógeno y hoy se muestran intensamente agrietadas y fracturadas en bloques de diversas dimensiones que van desde algunos metros cuadrados hasta kilómetros cuadrados. El macizo también es atravesado por diques de rocas básicas, predominantemente gabros y diabasas (Arango 1988).

Este trabajo tuvo el propósito de cartografiar los factores condicionantes y desencadentantes que generan peligro por deslizamientos en el mencionado municipio. La finalidad del mapa de zonificación del peligro por deslizamientos es dividir el área de interés en unidades homogéneas donde el grado de peligro sea semejante.

\section{MATERIALES Y MÉTODOS}

El estudio de la peligrosidad, vulnerabilidad y riesgo (PVR) requiere de la consideración de muchas variables. Para elaborar la metodología del estudio de peligro por deslizamientos en el municipio de Mayarí se siguieron las recomendaciones generales de los lineamientos metodológicos para estudios de PVR, realizados por el Grupo Nacional de Gestión de Riesgos del año 2012 y la Guía de estudios de riesgo para situaciones de desastre, elaborada por el Estado Mayor Nacional de la Defensa Civil (2005), así como otros trabajos realizados sobre esta temática (Castellanos 2012).

A fin de identificar las zonas que presentan deslizamientos se realizó la observación e interpretación del modelo digital del terreno (MDT), se revisaron los mapas topográficos de 1985 a escala 1: 25 000, del Instituto Cubano de Geodesia y Cartografía (ICGC) e imágenes aéreas obtenidas de Google Earth; además, sirvieron de apoyo los trabajos de campo, teniendo en cuenta eventos del pasado (Figura 2). 


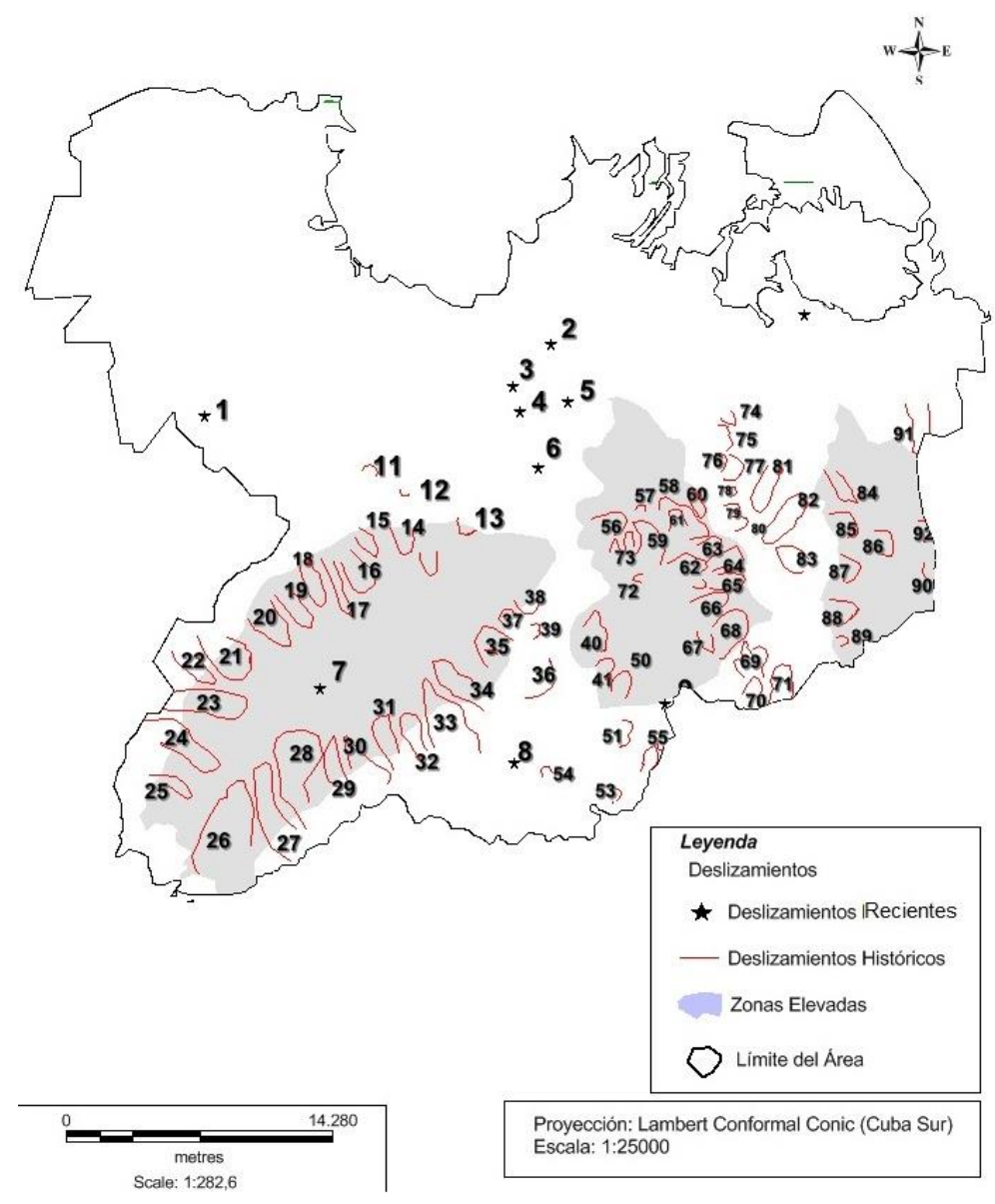

Figura 2. Mapa de inventario de deslizamientos del municipio de Mayarí.

Primeramente, diferentes tipos de mapas temáticos (intensas lluvias, redes hidrográficas, geomorfológico, geológico, uso de suelos y red vial) que representan los factores condicionantes y desencadenantes que inciden en la peligrosidad por deslizamientos en el municipio fueron evaluados, tomándose en consideración la tipología, la intensidad, el desarrollo, la dinámica y los mecanismos de formación de los deslizamientos en el área de estudio.

Posteriormente, se asignaron pesos a cada factor, dado que solo se requiere conocer, de manera general, las áreas que ofrecen peligro. Similares trabajos se han realizado en otros países (Varnes 1984; Carrara, Carratelli y Merenda 1991; Mora y Vahrson 1993). La particularidad de este estudio es que emplea los métodos heurísticos (Figura 3). 


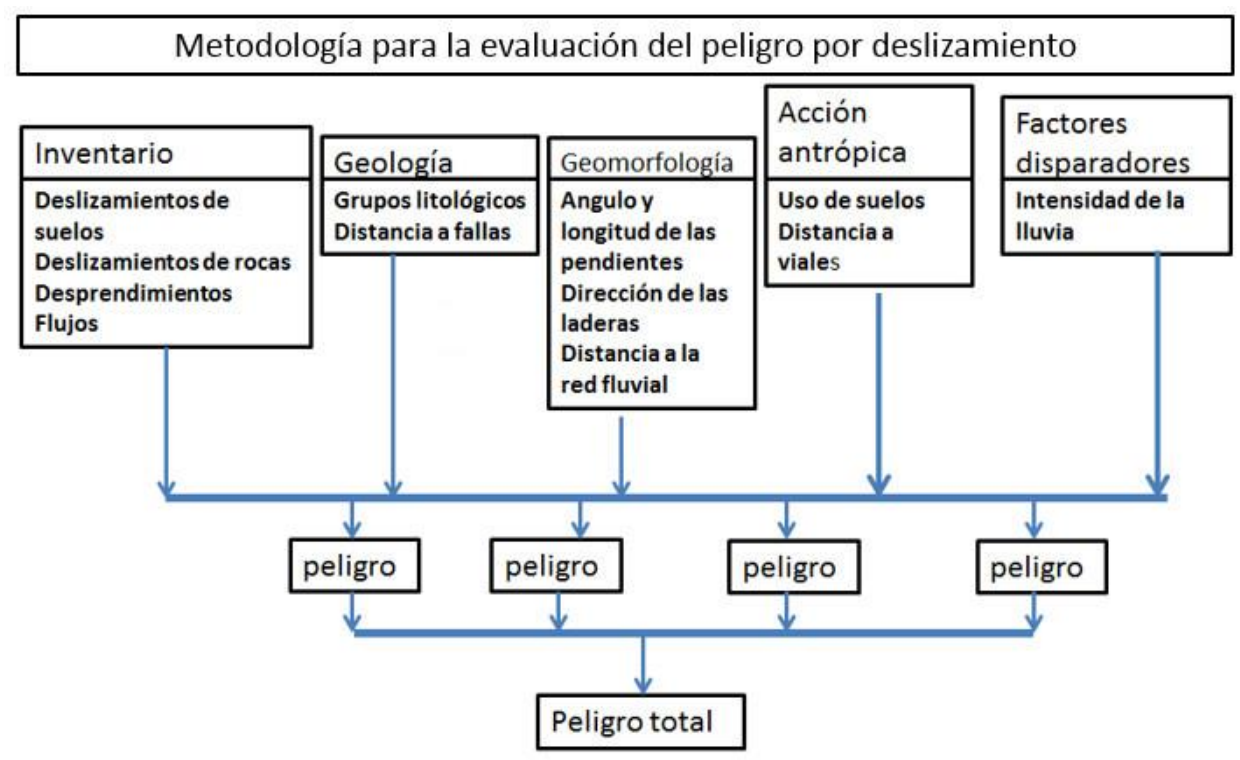

Figura 3. Esquema metodológico empleado para obtener la peligrosidad total por deslizamientos en el municipio de Mayarí.

\subsection{Descripción de los factores utilizados en el análisis de peligrosidad}

La evaluación espacial multicriterio emplea los niveles y pesos que se muestran en la Tabla 1. Los factores utilizados en el análisis fueron: geológicos, geomorfométricos, antrópicos y climáticos.

Tabla 1. Criterios en indicadores para el análisis de la peligrosidad por deslizamientos

\begin{tabular}{cccc}
\hline Criterio & Indicador & Peso & Estandarización \\
\hline \multirow{2}{*}{ Geológico } & Unidades geológicas & 0,9 & 5 clases de peligrosidad \\
& $\begin{array}{c}\text { Distancia a las fallas } \\
\text { Ángulo de pendiente }\end{array}$ & 0,1 & 5 cuartiles \\
& Relieve interno & 0,6 & 5 cuartiles \\
Geomorfométrico & $\begin{array}{c}\text { Distancia a la red } \\
\text { fluvial }\end{array}$ & 0,1 & 5 cuartiles \\
& Orientación de la & 0,1 & 9 clases por orientación \\
& $\begin{array}{c}\text { pendiente } \\
\text { Antrópico de suelo }\end{array}$ & 0,5 & 5 clases de peligrosidad \\
& Distancia a la red vial & 0,5 & 5 cuartiles \\
Climático & Precipitación media & 1,0 & 5 cuartiles \\
& anual & & \\
\hline
\end{tabular}




\subsection{Factor geológico}

Grupos litológicos: para el análisis litológico se empleó la clasificación propuesta por Mora y Vahrson (1993), teniendo en cuenta las características geológicas y geotécnicas. El área se clasificó en seis grupos litológicos: sedimentos costeros, sedimentos de ríos, carbonatada terrígena, vulcanógena sedimentaria, gabros del complejo ofiolítico, peridotitas y harzburgitas del complejo ofiolítico.

Distancia a las fallas: el análisis de distancia a las fallas fue realizado por la interpretación del mapa tectónico del municipio de Mayarí. La información se obtuvo a partir del análisis del MDT del área en estudio a escala 1: 25000 y la interpretación de fotos aéreas, donde se consideraron los criterios de identificación de fallas como son, la alineación de estructuras geológicas y ríos, presencia de escarpes de falla, cambio brusco de litología, entre otras. Como resultado se obtuvo un buffer de distancia a fallas, con un radio de $100 \mathrm{~m}$. El mapa fue dividido en cinco intervalos, con el objetivo de representar la influencia de las fallas en el medio.

\subsection{Factor geomorfométrico}

Ángulo de la pendiente: para analizar este factor se utilizó la pendiente del terreno. El mapa se realizó a partir del MDT del municipio, a escala 1: 25 000. Los intervalos de pendiente seleccionados se tomaron según estudio de Kamp y demás colaboradores (2008). De esta forma, se presenta un mapa clasificado en cinco intervalos: $0^{\circ}-15^{\circ}, 15^{\circ}-25^{\circ}, 25^{\circ}-35^{\circ}$, $35^{\circ}-45^{\circ}$ y $>45^{\circ}$.

Distancia a la red fluvial: para analizar este factor se empleó la red fluvial, en la que se representan los principales ríos del área, así como sus afluentes secundarios. Según el mapa, la red fluvial es muy densa, hacia el norte y sur; estas son de tipo dendrítica y los ríos principales corren siguiendo las principales direcciones de las fallas, teniendo como principal cuenca la del río Mayarí. La información se obtuvo mediante la interpretación de cartas topográficas del ICGC, a escala 1: 25000 , y a partir de la correlación con el MDT a igual escala. Se realizó un análisis de la influencia de la distancia a los ríos y arroyos en la ocurrencia de deslizamientos. Para ello, se confeccionó un buffer de la red fluvial con un radio de $100 \mathrm{~m}$ en cinco intervalos.

Orientación de la pendiente: para analizar este factor se utilizó la dirección de laderas. El mapa se realizó, a partir del MDT, a escala 1: 25000. El mapa se divide en nueve clases para cada dirección y la clase 1 para los pixeles planos. 


\subsection{Factor antrópico}

Uso de suelos: el factor de uso de suelos se trabajó a partir de fotos cósmicas y fue enriquecido con bases cartográficas digitales del municipio. La información procesada referente al uso de suelo está dividida en 15 clases, estas son: asentamiento poblacional, café, cultivos varios, embalses, pastos naturales, minas, empresas, depósitos de cola, aeropuerto, puerto, campismo, carreteras, ferrocarril, vegetación y parque nacional La Mensura.

Distancia a la red vial: el mapa de red vial se obtuvo a partir del mapa ofrecido por la Defensa Civil del municipio, el cual brinda la información de las carreteras principales y secundarias, así como de los caminos del municipio. Este factor se aplicó mediante el análisis de la distancia de la red vial a la ocurrencia de deslizamientos. Como resultado se obtuvo un buffer de $100 \mathrm{~m}$ de radio en cinco intervalos a las carreteras y caminos.

\subsection{Factor climático}

Máxima intensidad de lluvia en 24 horas para un período de retorno de 100 años. En este factor se consideró el período de ocurrencia de las Iluvias medias anuales. El mapa se confeccionó a partir de la base de datos del Instituto Nacional de Recursos Hidráulicos (INRH) de máxima intensidad de lluvia en 24 horas, para un periodo de retorno de 100 años. Este factor es de gran importancia para el análisis de riesgo por deslizamientos debido a la influencia que ejerce sobre el macizo, al aumentar su presión de poros y provocar los deslizamientos.

\section{RESULTADOS Y DISCUSIÓN}

\subsection{Evaluación de los mapas de peligrosidad}

\subsubsection{Peligrosidad por el factor geológico}

\section{Grupos litológicos}

La peligrosidad muy alta se asocia a las peridotitas, harzburgitas y los gabros de complejo ofiolíticolas, los cuales se sumaron al mismo grupo litológico por sus características y propiedades físico-mecánicas. Constituyen el 50,3\% del área total porque, generalmente, estas rocas se encuentran muy agrietadas y meteorizadas.

La peligrosidad alta la determina el grupo de las rocas vulcanógenas sedimentarias que ocupan el $8,1 \%$ del área total. La peligrosidad moderada está representada por el grupo de las rocas carbonatadas terrígenas con 
un 25,6\% del área total. La peligrosidad baja está constituida por los sedimentos de ríos con un $2,7 \%$ del área total. La peligrosidad muy baja la integran los sedimentos costeros con un 13,07 \% del área total (Figura 4).

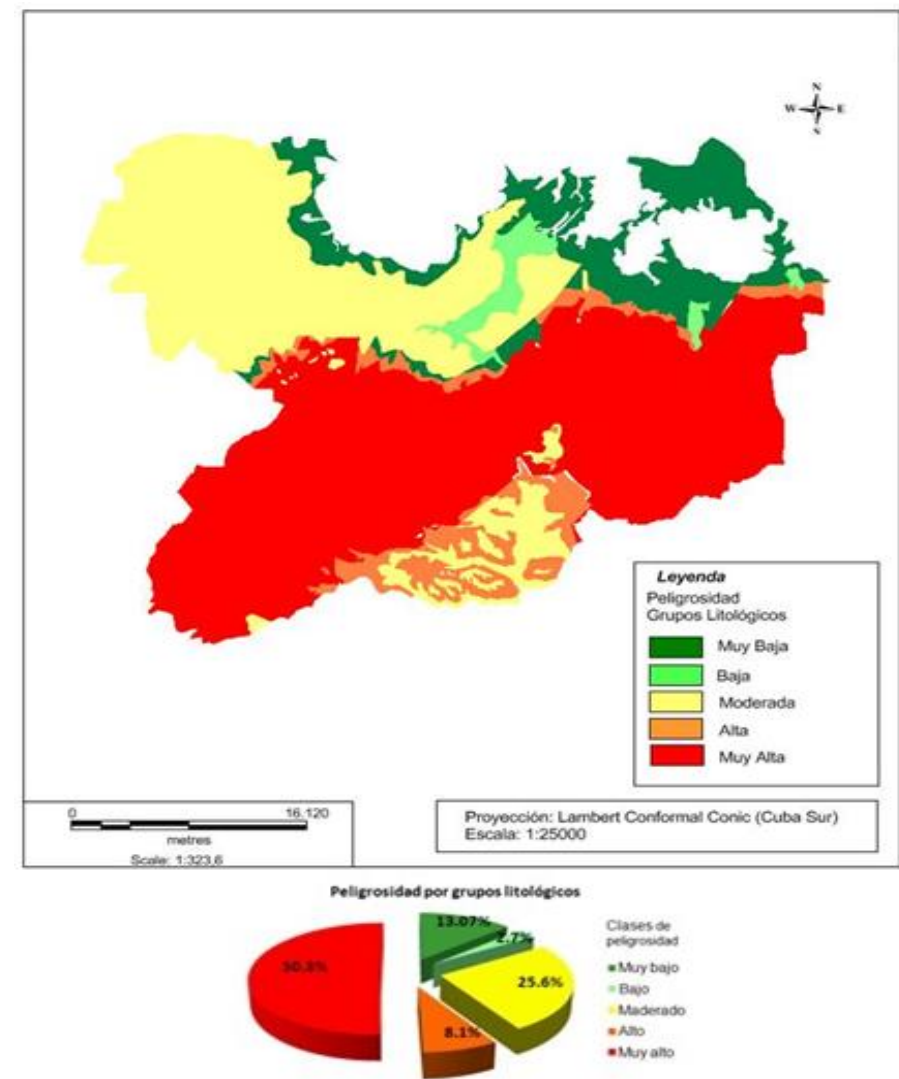

Figura 4. Peligrosidad por grupos litológicos del municipio de Mayarí.

Distancia a las fallas

Para analizar la influencia de este factor sobre la peligrosidad del terreno, mediante el SIG (Figura 5), se aplicó un buffer a partir de las estructuras principales del plano tectónico. La tectónica del área se caracteriza por una elevada complejidad con la presencia de varios sistemas de fallas de gran importancia e influencia en el debilitamiento del macizo estudiado y en la formación de deslizamientos. El buffer se dividió en cinco intervalos de radios de $100 \mathrm{~m}$ y se clasificó en cinco clases de peligrosidad (muy alta, alta, moderada, baja y muy baja).

La peligrosidad muy alta frente al desarrollo de deslizamientos la representa la distancia a $100 \mathrm{~m}$, debido a que las rocas en esta zona se encuentran fuertemente agrietadas y fracturadas por la influencia directa de las fallas, las que se pueden convertir en superficie de rotura para el desarrollo de los deslizamientos; ocupan $7,1 \%$ del área total. 
La peligrosidad alta está representada por la distancia a $200 \mathrm{~m}$ que abarca 7,6 \% del área total. La peligrosidad moderada es a $300 \mathrm{~m}$ de distancia y contiene $7,8 \%$ del área total.

La peligrosidad baja representa la distancia a $400 \mathrm{~m}$ y engloba 7,6 \% del área total. La peligrosidad muy baja corresponde con la distancia a $500 \mathrm{~m}$ y es la que comprende mayor extensión: el 69,6\% del área total.

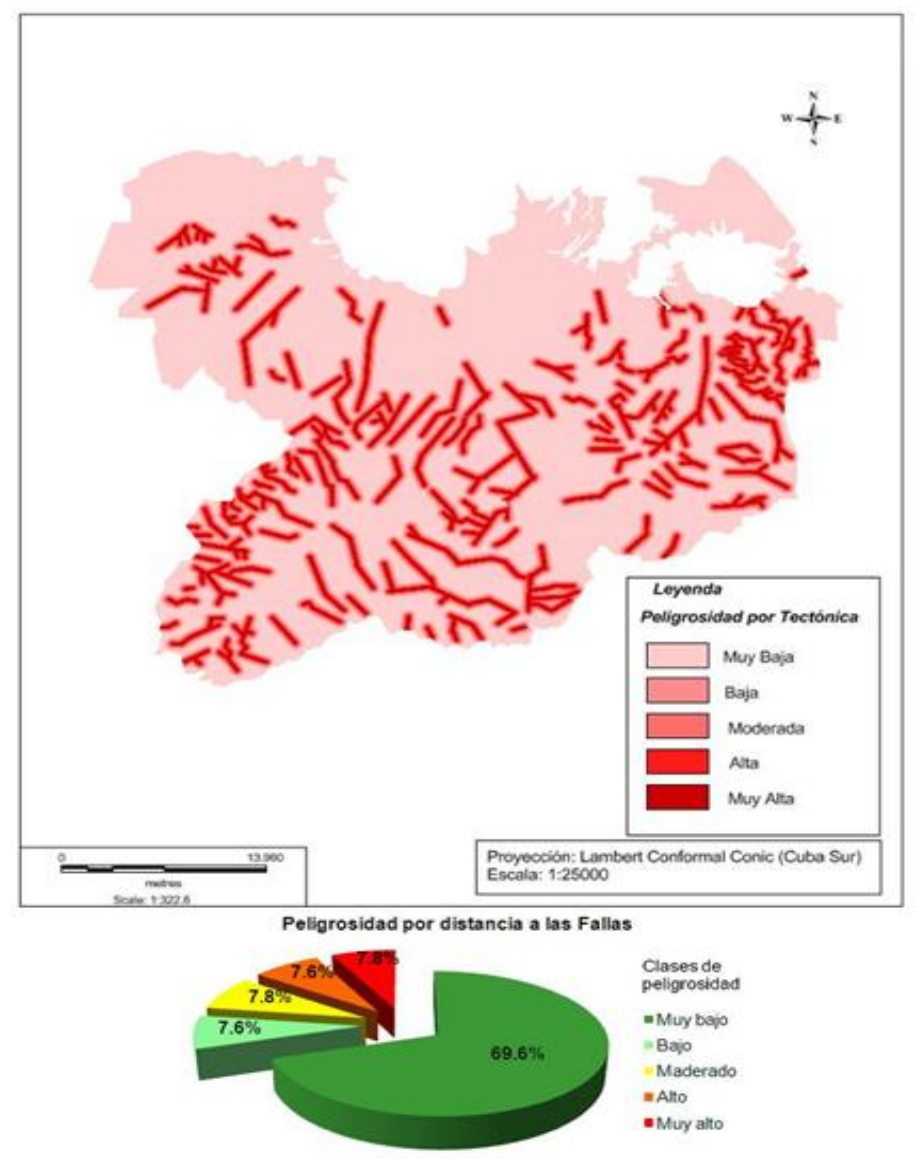

Figura 5. Peligrosidad por distancia a las fallas del municipio de Mayarí.

\subsubsection{Peligrosidad por el factor geomorfométrico}

Ángulo de la pendiente

La pendiente del terreno es uno de los elementos geomorfológicos más importantes en el análisis del riesgo por deslizamiento. En el mapa (Figura 6) se observa que los mayores grados de pendientes se encuentran en el borde de la meseta Pinares y hacia el sureste del área de estudio. El mapa de pendiente se clasificó en cinco clases de peligrosidad (muy alta, alta, moderada, baja y muy baja), de acuerdo con el peligro que representan frente a los movimientos de masas. 
La peligrosidad muy alta se relaciona con las mayores pendientes $\left(>45^{\circ}\right)$ debido a que los deslizamientos son de carácter gravitatorio y en estas zonas es donde se acumula mayor cantidad de energía en los taludes y laderas, comprendiendo el 19,8 \% del área total. La clase de peligrosidad alta se corresponde con las pendientes de $35^{\circ}-45^{\circ}$ y engloba el $9,9 \%$ del área.

La clase de peligrosidad moderada coincide con las pendientes $25^{\circ}-35^{\circ}$, abarcando el $17,6 \%$ del área total. La clase de peligrosidad baja está vinculada con pendientes de $15^{\circ}-25^{\circ}$ y ocupa el $7,8 \%$ del área. La clase de peligrosidad muy baja se ajusta con el intervalo de pendiente $0^{\circ}-15^{\circ}$ y comprende la mayor extensión: 47,7\% del área total. Se puede observar que el $47,3 \%$ del área total se encuentra desde la peligrosidad moderada hasta la muy alta.

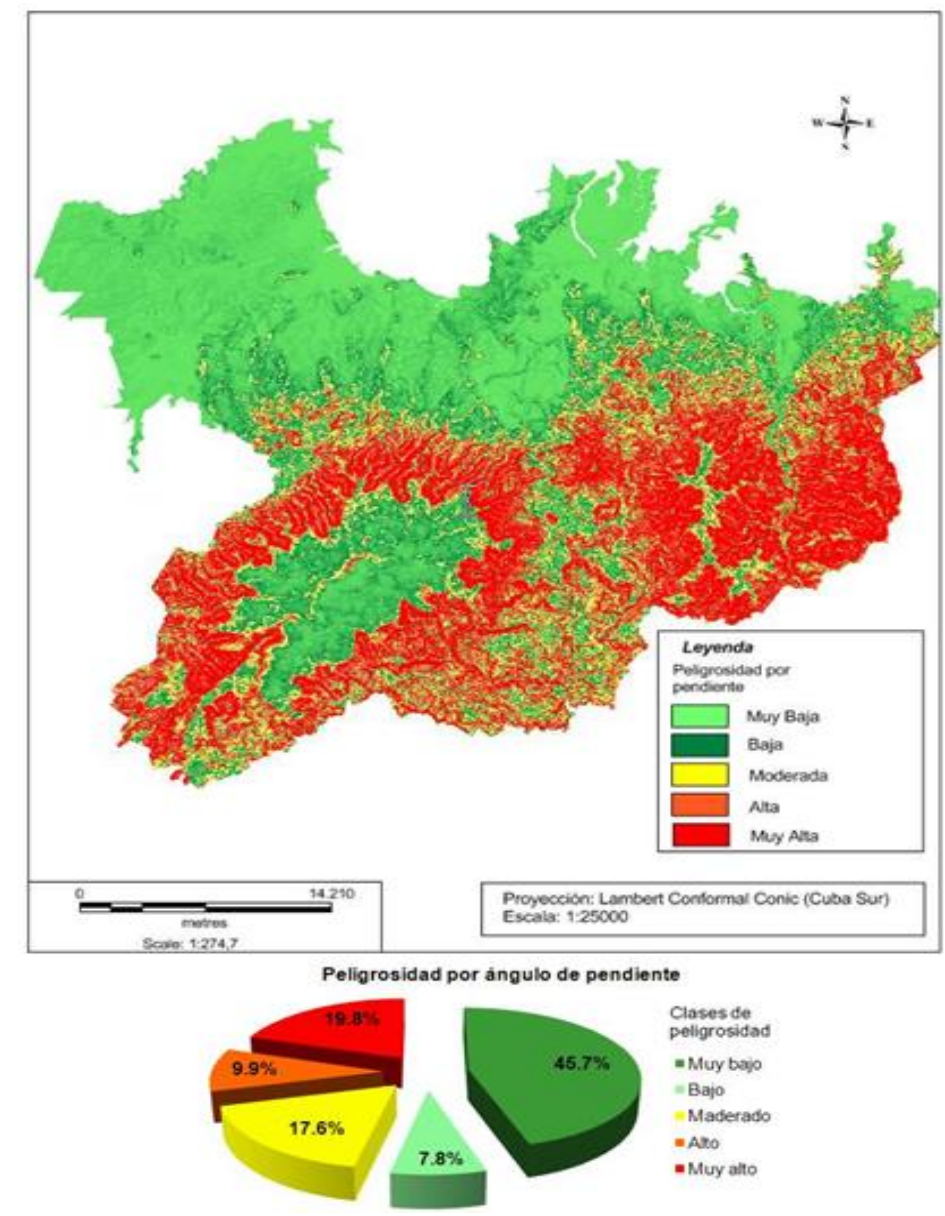

Figura 6. Peligrosidad por ángulo de la pendiente del municipio de Mayarí.

\section{Distancia a la red fluvial}

Para incluir este factor en el SIG y analizar su influencia sobre el desarrollo de deslizamientos se aplicó un análisis de distancia, utilizando la 
herramienta buffer. El buffer se dividió en cinco intervalos de $100 \mathrm{~m}$ de distancia $(100 \mathrm{~m}, 200 \mathrm{~m}, 300 \mathrm{~m}, 400 \mathrm{~m}$ y $500 \mathrm{~m}$ ) y se clasificó en cinco clases de peligrosidad (muy alta, alta, moderada, baja y muy baja).

La peligrosidad muy alta frente al desarrollo de deslizamientos la representa la distancia a 100 m, ocupa 10,95 \% del área total. La peligrosidad alta está representada por la distancia a $200 \mathrm{~m}$ que comprende el 10,41 \% del área total. La peligrosidad moderada es a $300 \mathrm{~m}$ de distancia y contiene 10,04\% del área total.

La peligrosidad baja representa la distancia a $400 \mathrm{~m}$ y abarca 9,2 \% del área total. La peligrosidad muy baja correspondiente con la distancia a 500 m es la que engloba mayor extensión: 59,2 \% del área total (Figura 7).

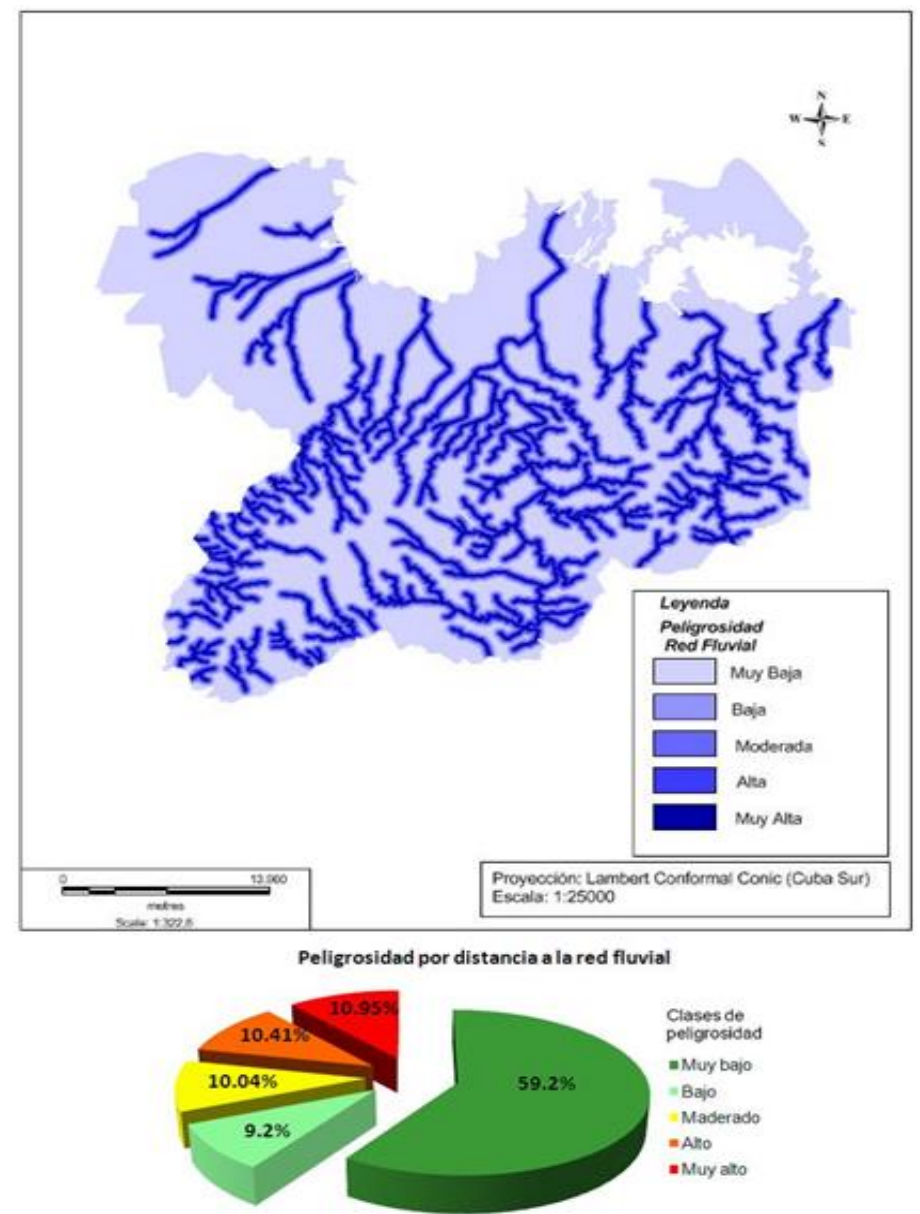

Figura 7. Peligrosidad por distancia a la red fluvial del municipio de Mayarí.

\section{Dirección de laderas}

El mapa de peligrosidad por dirección de laderas (Figura 8) se clasificó en cinco clases de peligrosidad (muy alta, alta, moderada, baja y muy baja), de acuerdo con el peligro que representan frente a los movimientos de 
masas. Predominan las direcciones hacia el norte $(18,26 \%)$, noroeste $(15,49 \%)$ y oeste $(16,45 \%)$. Dentro de los agentes que influyen en la formación de deslizamientos por la dirección de laderas se incluyen la exposición a la luz del sol, los vientos y las Iluvias (Dai, Lee y Xu 2001).

Por consiguiente, es razonable asumir que la peligrosidad muy alta está representada por las direcciones de laderas norte que ocupan el 18,26\% del área total y la peligrosidad alta se representa por las direcciones de laderas noreste y noroeste, comprendiendo el 24,49 \% del área total, ya que son las más susceptibles a sufrir deslizamientos detonados por lluvias debido a que en estas zonas las precipitaciones son más frecuentes.

La peligrosidad moderada está representada por las direcciones de laderas este y oeste, abarcando el $26,45 \%$ del área total. Por otra parte, se considera que las menos susceptibles son las direcciones de laderas suroeste y sureste, representando la peligrosidad baja que comprenden el $16,3 \%$ del área total, y la dirección de laderas del sur, que representa la peligrosidad muy baja y engloba $14,5 \%$ del área total, pues permanecen bajo la sombra donde las lluvias no son muy intensas, por lo que son zonas más secas.

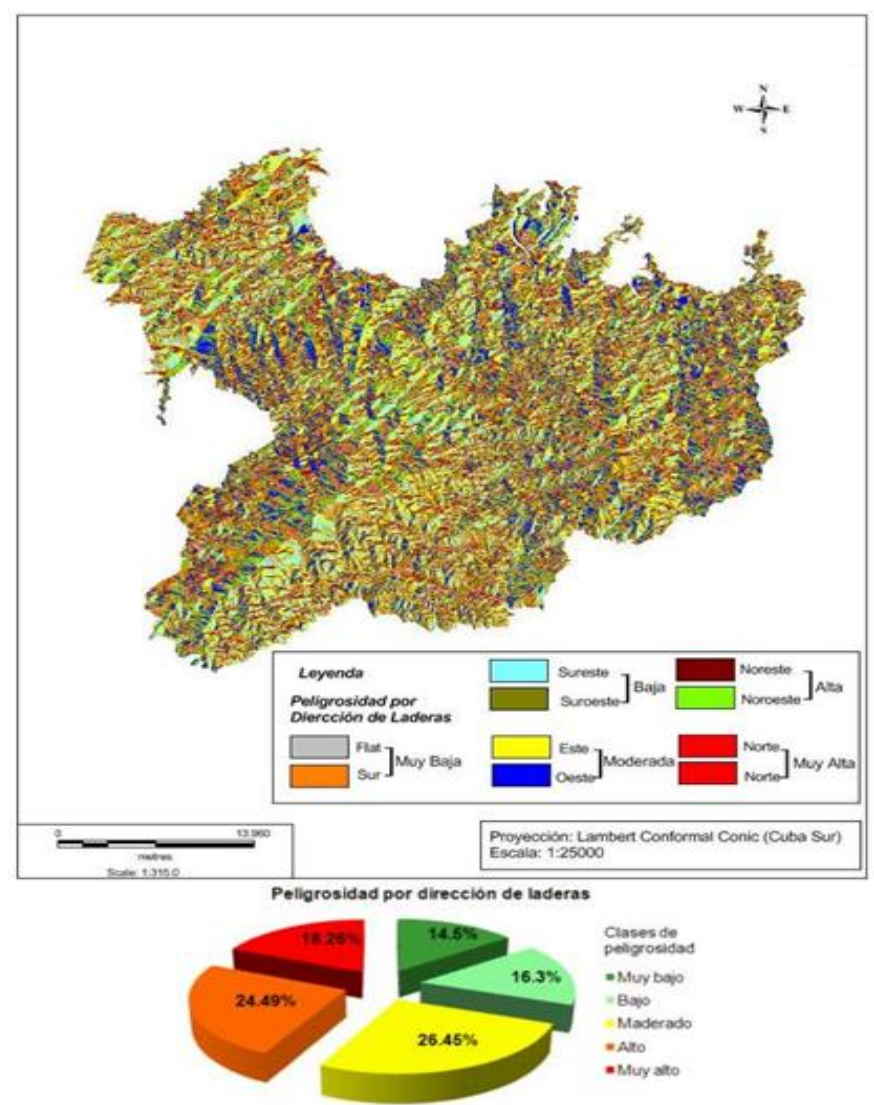

Figura 8. Peligrosidad por direccion de laderas del municipio de Mayarí. 


\subsubsection{Peligrosidad por el factor antrópico}

Uso de suelos

El mapa de uso de suelos (Figura 9) se clasificó en cinco clases de peligrosidad (muy baja, baja, moderada, alta y muy alta), teniendo en cuenta la importancia económica, física y social de cada tipo de uso del suelo. La clase de peligrosidad muy baja es la de mayor área y representa el 58,2 \% del área total, constituida fundamentalmente por los bosques; mientras que la peligrosidad baja ocupa el 22,5\% del área total, compuesta generalmente por los parques nacionales y las plantaciones de caña y pastos. La clase de peligrosidad moderada contiene el 6,14 \% del área total, del mismo modo las peligrosidades alta y muy alta comprende un $1,77 \%$ y $11,21 \%$ del área total, respectivamente, representadas fundamentalmente por minas, presas, empresas, cultivos y asentamientos poblacionales.

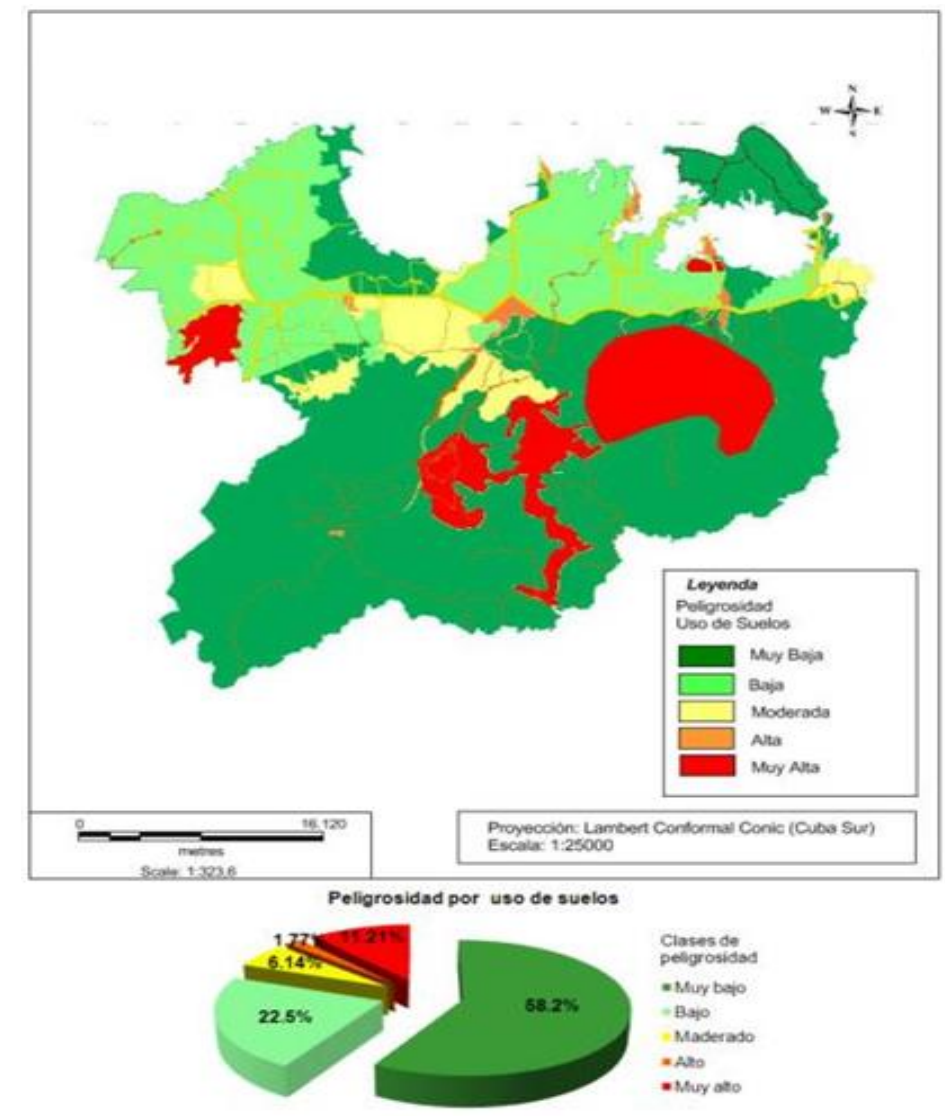

Figura 9. Peligrosidad por uso de suelos del municipio de Mayarí.

Distancia a la red vial

Para analizar este factor, se toma en consideración la influencia que tienen los viales sobre el desarrollo de deslizamientos, pues en ocasiones se 
construyen carreteras y caminos cortando laderas de altas pendientes y formando taludes abruptos, favorables para la ocurrencia de deslizamientos. Para ello se aplicó un análisis de distancia utilizando la herramienta buffer. El buffer se dividió en cinco intervalos de $100 \mathrm{~m}$ de distancia (100 m, 200 m, 300 m, $400 \mathrm{~m}$ y $500 \mathrm{~m}$ ) y se clasificó en cinco clases de peligrosidad (muy alta, alta, moderada, baja y muy baja).

La peligrosidad muy alta frente al desarrollo de deslizamientos la representa la distancia a $100 \mathrm{~m}$; ocupa 8,02 \% del área total; la distancia a $200 \mathrm{~m}$ representa la peligrosidad alta, comprende $7,6 \%$ del área total; la clase de peligrosidad moderada es a $300 \mathrm{~m}$ de distancia y contiene 7,2 \% del área total; la peligrosidad baja representa la distancia a $400 \mathrm{~m}$ con un 6,8\% del área total. Por último, la peligrosidad muy baja, correspondiente con la distancia a $500 \mathrm{~m}$, es la que abarca mayor extensión: 48,26 \% del área total (Figura 10).

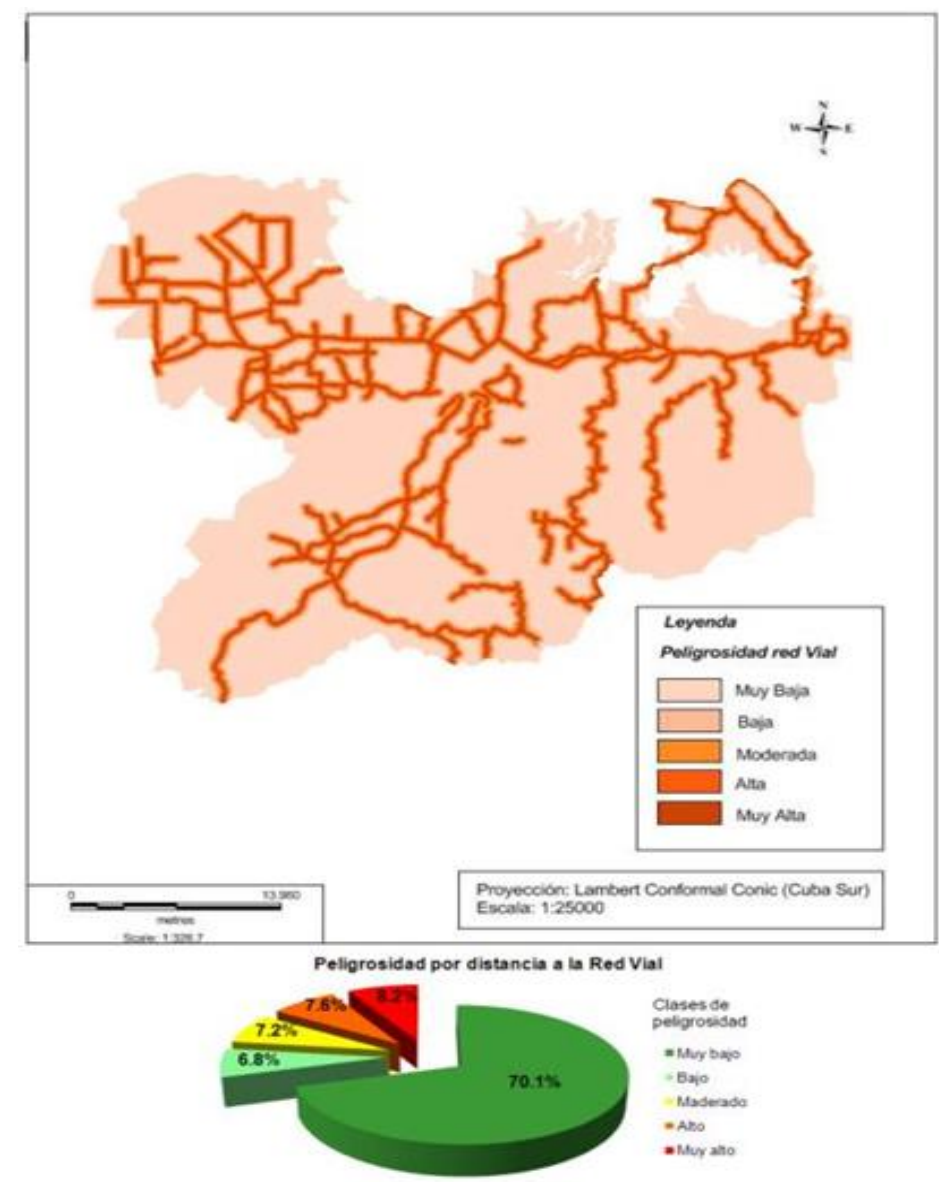

Figura 10. Peligrosidad por red vial del municipio de Mayarí.

\subsubsection{Peligrosidad por el factor climático}

De acuerdo al análisis realizado, el factor intensidad de lluvia en 24 horas para un período de retorno de 100 años ejerce gran influencia en el 
desarrollo de los movimientos de masas, al incidir directamente sobre el medio geológico. El mapa (Figura 11) muestra que hacia las zonas sureste, centro y este los valores de intensidad de lluvia son muy elevados, alcanzando rangos mayores de $426 \mathrm{~mm}$.

Al correlacionar esta información con el mapa de inventario de deslizamientos se observa claramente que por encima de estos valores se originaron la mayoría de los deslizamientos reportados. Este factor actúa principalmente provocando una saturación del macizo rocoso, al infiltrarse al agua a través de las grietas y poros va lixiviando el relleno que mantiene unido el material rocoso, lo que origina un aumento de la masa del macizo que ocasiona su desprendimiento a través de zonas de debilidad.

El mapa de peligrosidad por intensidad de lluvia en 24 horas para un período de retorno de 100 años se divide en cinco clases (muy alta, alta, moderada, baja y muy baja). La clase de peligrosidad muy baja representa el 3,3\% del área total; la peligrosidad baja constituye un 1,8\% del área total; la clase de peligrosidad moderada ocupa la mayor extensión del área: 8,9\%; la peligrosidad alta es la de mayor extensión en el área representada por el $67,3 \%$ del total.

Por su parte, la peligrosidad muy alta significa el $18,6 \%$ del área total, con valores de intensidad de las lluvias mayores a $426 \mathrm{~mm}$, donde el 94,8 \% del área se encuentra representada por las clases de peligrosidad, desde la moderada hasta la muy alta. 


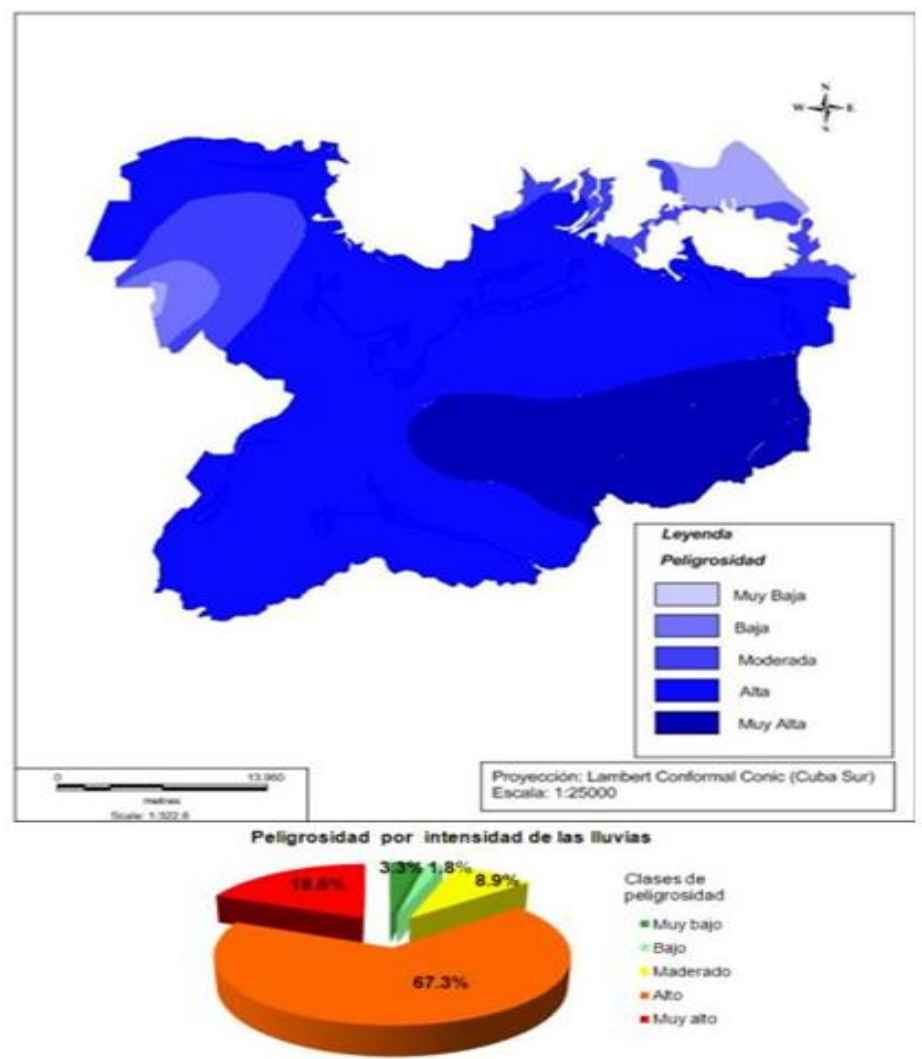

Figura 11. Peligrosidad por intensidad de lluvias en 24 horas para un período de retorno de 100 años del municipio de Mayarí.

\subsection{Caracterización del mapa de peligrosidad total por deslizamientos del municipio de Mayarí}

El mapa de peligrosidad por deslizamientos en el municipio de Mayarí (Figura 12) se obtuvo a partir de la integración de los mapas de peligrosidad de cada factor condicionante y desencadenante analizado (mapa litológico, mapa de ángulo de la pendiente, mapa dirección de laderas, mapa de uso de suelos, mapas de influencia de la red fluvial y red vial, mapa de distancia a fallas y mapa pluviométrico), utilizando el SIG. El mapa posee un alto valor práctico, desde el punto de vista geoambiental, porque delimita las áreas en las que puede existir la mayor probabilidad de ocurrencia de deslizamientos.

Se establecen niveles de peligrosidad a partir del peso asignado a cada factor. Las zonas con peligrosidad de moderada hasta muy alta se localizan hacia el este, centro y suroeste, fundamentalmente, aunque se observan, además, en la parte sur del área.

Las zonas con peligrosidad alta y muy alta se relacionan, generalmente, con rocas ultrabásicas serpentinizadas y gabros, ambas con alto grado de agrietamiento e intemperismo. Estas zonas se localizan en laderas de altas 
pendientes y donde se tienen los mayores valores pluviométricos reportados; asimismo, se corresponden con zonas de fallas, nudos tectónicos o cercanos a cauces de ríos.

El uso de suelo es también determinante, pues el manejo minero-productivo y la construcción de obras hidráulicas que generan la aceleración de los agentes exógenos condicionan los procesos erosivos $y$, en ocasiones, provocan deslizamientos o inestabilidades de taludes y laderas. Otra de las condicionantes son las intensas lluvias que se manifiestan en el territorio, donde la intensidad de las lluvias en 24 horas para un periodo de retorno de 100 años sobrepasan los $426 \mathrm{~mm}$.

Esto genera un aumento, en un corto tiempo, del peso del suelo y de las presiones neutras o de poros, disminuyendo la cohesión y fricción interna de las rocas arcillosas y areno-arcillosas. A partir del mapa de peligro y el de inventario de deslizamiento se elaboró un mapa que vincula los deslizamientos con las zonas de mayor peligrosidad, el cual permite demostrar el porqué de los altos índices de peligrosidad en el área, coincidiendo estos con las zonas donde se encuentran los mayores números de deslizamientos.

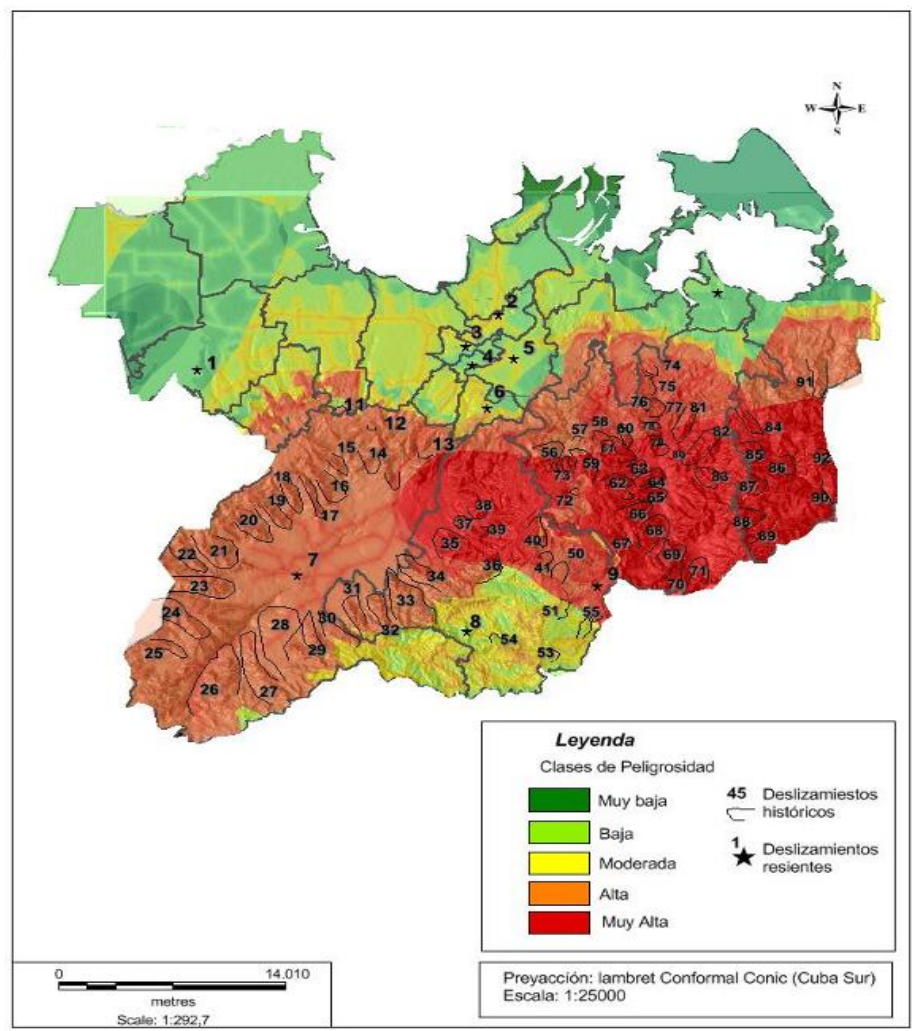




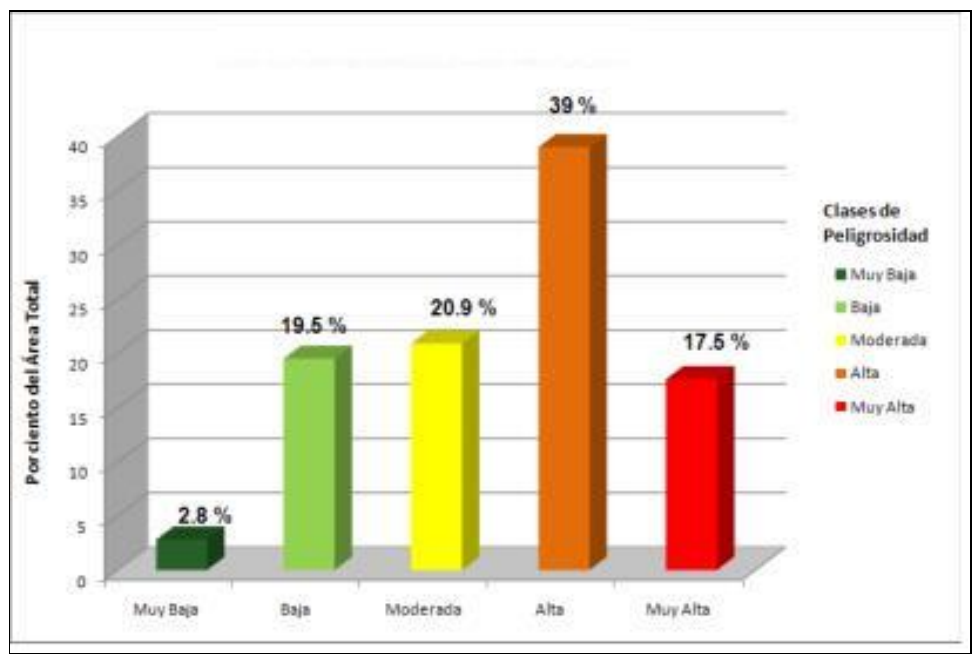

Figura 12. Mapa e histograma de peligrosidad por deslizamientos para un período de retorno de 100 años. Municipio de Mayarí.

Los factores utilizados para evaluar la peligrosidad por deslizamientos en el municipio de Mayarí, los grupos litológicos, influencia de las fallas activas, red fluvial, red vial, uso del suelo dirección y ángulo de las pendientes e intensidad de las lluvias, evidenciaron su relación con el desarrollo de este fenómeno. Las variables consideradas representan diferentes características del posible comportamiento del fenómeno geológico en su tipología: desprendimientos, flujos, deslizamientos y expansiones laterales.

La implementación de las técnicas SIG han permitido crear una base de datos y analizar la información relacionada con la base temática y superponer estas capas correspondientes a cada variable que interviene en la evaluación de la peligrosidad por deslizamientos.

Teniendo en cuenta los factores que intervienen en los procesos de deslizamientos se elaboraron los diferentes mapas, los que se combinaron para obtener el mapa de peligrosidad total, que muestra el nivel de peligrosidad existente en el municipio Mayarí.

\section{CONCLUSIONES}

- Los principales tipos de movimientos de masas rocosas en el municipio son desprendimientos, deslizamientos, flujos y expansiones laterales, los que están diferenciados por su génesis, estructura y tipo de material. Los factores causales y condicionales que generan los deslizamientos son la geomorfometría, geología, actividad antrópica y el clima.

- La obtención del mapa de peligrosidad por deslizamientos en el municipio de Mayarí permite categorizar el nivel de peligrosidad. Este 
resultado aporta información básica para realizar la evaluación geoambiental, el diseño de planes y el ordenamiento territorial en el área de estudio.

- Los escenarios de mayor peligro en el municipio de Mayarí se encuentran en los consejos populares: Pinares de Mayarí, Arroyo Seco, Levisa, Cajimaya y Cabonico, en los cuales se combinan varios de los factores que favorecen los deslizamientos como son: geomorfometría, geología, acción antrópica e intensidad de las lluvias.

\section{REFERENCIAS}

Arango, A. 1988: Informe Geológico. Proyecto C.H.A de Río Guayabo y Río Sojo. Holguín. 24 p.

Carrara, A.; Carratelli, E. P. y Merenda, L. 1991: Computer-based data bank and statistical analysis of slope instability phenomena. Zeitschriftfüreo morphologie, 21: 187-222.

Castellanos, E. 2012: Guía metodológica para el estudio de peligro, vulnerabilidad $y$ riesgo por deslizamientos de terreno a nivel municipal. Versión 4-enero. La Habana: Ministerio de Ciencia, Tecnología y Medio Ambiente. 31 p.

Centro de Investigaciones y Servicios Ambientales -CISAT. 2007: Diagnóstico ambiental de la cuenca del río Mayarí. Holguín. 151 p.

Dai, F. C.; Lee, C. F. y Xu, Z. W. 2001: Assessment of landslide susceptibility on the natural terrain of Lantau Island, HongKong. Environmental Geology, 40(3): 381-391.

Estado Mayor Nacional de la Defensa Civil de la República de Cuba. 2005: Guía para la realización de estudios de riesgo para situaciones de desastres. La Habana. 30 p.

Grupo Nacional de Evaluación de Riesgos. 2012: Lineamientos metodológicos para la realización de los estudios de peligro, vulnerabilidad $y$ riesgo de desastres de inundaciones por penetración del mar, inundación por intensas lluvias y afectaciones por fuertes vientos. La Habana: Ministerio de Ciencia, Tecnología y Medio Ambiente. 40 p.

Kamp, U.; Growley, B. J.; Khattakg, A. y Owen, L. A. 2008: GISbased landslide susceptibilitymapping for the 2005 Kashmir earthquake region. Geomorphology, 101(4): 631-642. 
Mora, S. y Vahrson, W. G. 1993: Determinación "a priori" de la amenaza de deslizamientos utilizando indicadores morfodinámicos. Tecnología ICE, 3(1): 32-42.

Proenza, J. 1998: Mineralización de cromita en la faja ofiolítica Mayarí-Baracoa (Cuba). Ejemplo del yacimiento Merceditas. Tesis doctoral. Universidad de Barcelona. 227 p.

Varnes, D. J. 1984: Landslide Hazard Zonation: a review of principles and practice. París: UNESCO. 63 p. ISBN: 92-3-101895-7.

Recibido: 27/04/2017

Aceptado: 29/05/2018 